DOI: $10.22363 / 2312-9182-2018-22-3-539-559$

\title{
A Semantic Menagerie: The Conceptual Semantics of Ethnozoological Categories
}

\author{
Cliff Goddard \\ Griffith University \\ 170 Kessels Road, Nathan, Queensland 4111 Australia
}

\begin{abstract}
Following the seminal work of Wierzbicka $(1985,2013)$, this paper proposes and discusses a set of semantic analyses of words from three different levels of the English ethnozoological taxonomic hierarchy (Berlin 1992): creature (unique beginner), bird, fish, snake, and animal (life-form level), dog and kangaroo (generic level). The analytical framework is the Natural Semantic Metalanguage approach (Wierzbicka 1996, 2014, Goddard and Wierzbicka 2014). Though ultimately resting on the foundational elements of the NSM system, i.e. 65 semantic primes and their inherent grammar of combination, the analysis relies on the analytical concepts of semantic molecules and semantic templates (Goddard 2012, 2016). These provide mechanisms for encapsulating semantic complexity and for modelling relations between successive layers of the hierarchy. Other issues considered include the extent to which cultural components feature in the semantics of ethnozoological categories, and the extent to which semantic knowledge may vary across different speech communities.
\end{abstract}

Keywords: lexical semantics; NSM; ethnozoology; semantic complexity; semantic molecules; Anna Wierzbicka

\section{Семантическая менажерия: концептуальная семантика этнозоологических категорий}

\author{
Клифф Годдард \\ Университет Гриффит \\ 170 Kessels Road, Nathan, Queensland 4111 Australia
}

\begin{abstract}
Аннотация
Основываясь на фундаментальных работах Анны Вежбицкой (Wierzbicka 1985, 2013), автор статьи предлагает семантический анализ слов, принадлежащих к разным уровням английской этнозоологической иерархии (Berlin 1992): creature (первичная форма жизни), bird, fish, snake, animal (уровень жизненных форм), dog, kangaroo (родовой уровень). В работе используется подход Естественного Семантического Метаязыка (ЕСM) (Wierzbicka 1996, 2014; Goddard and Wierzbicka 2014). Используя основополагающие принципы ЕСМ, то есть 65 семантических примитивов и присущую им грамматику сочетаемости, анализ основывается на аналитических концептах семантических молекул и семантических моделей (Goddard 2012, 2016). Они предоставляют механизмы для отражения семантической сложности и моделирования отношений между последовательными уровнями
\end{abstract}


иерархии. В работе также рассматриваются вопросы степени присутствия культурных компонентов в семантике этнозоологических категорий и степени различия семантического знания между языковыми сообществами.

Ключевые слова: лексическая семантика, Естественный Семантический Метаязык (ЕСМ), этнозоология, семантическая сложность, семантические молекулы, Анна Вежбицкая

\section{BACKGROUND}

There is an enormous literature on natural kind concepts. In ethnobiology the major reference points include Berlin (1972, 1992), Brown (1977), and Atran (1990), in philosophy Kripke (1977), and in cognitive psychology Rosch (1977, 1978). In linguistic semantics, the foundational work is Wierzbicka (1985), building on Apresjan (1969, 1992 [1974]).

Across this literature, there is broad agreement that it makes sense to recognise taxonomic hierarchies (Berlin 1992), with the words at each rank being semantically more general and wider in their denotative range than the ones below them. The maximum number of levels, not found in all languages or in all domains, is said to be five: unique beginner $>$ life-form $>$ generic $>$ specific $>$ varietal. Berlin claims, however, that all languages distinguish at least two levels: life-form and generic. This paper proposes a set of semantic analyses (explications) of words from three levels of the English ethnozoological taxonomic hierarchy: creature (unique beginner), bird, fish, snake, and animal (life-form level), dog and kangaroo (generic level).

\subsection{Framework}

The analytical framework is the Natural Semantic Metalanguage approach (Wierzbicka 1996, Goddard and Wierzbicka 2014), a system of meaning representation based on a small inventory of fundamental, indefinable elements of meaning: semantic primes. They are listed in Appendix A using English exponents. Comparable lists exist for about 30 languages.

Semantic primes have an inherent syntax which allows them to be combined into phrases, sentences and texts. Evidence suggests that this syntax is language-independent, in the sense that the same combinations can be realised in all or most languages. As well as simple combinatorial possibilities (e.g. 'something good/bad', 'in many places'), semantic primes can have extended valency and complement options. Language-specific variant forms or "allolexes", and portmanteau expressions, are also allowed, e.g. English else for other, often for 'at many times'. Together, semantic primes and their associated grammar make up the core of the Natural Semantic Metalanguage. In addition to semantic primes, many explications require the use of various semantic molecules (Goddard and Wierzbicka 2014, Goddard 2016). These are complex meanings, themselves definable in terms of semantic primes, that function alongside primes as building blocks of linguistic meaning. They are marked with [m] to distinguish them from semantic primes. Cross-linguistic research indicates that semantic primes, and many important semantic molecules, are expressible lexically in all or most languages ${ }^{1}$.

1 The metalanguage of the explications reflects the version current in 2018, sometimes termed NSM4 (Goddard 2018: 36). 
Using this metalanguage allows researchers to decompose complex languagespecific meanings into text-like configurations (semantic explications) of simple crosstranslatable concepts. Explications for a given semantic subclass typically follow a consistent semantic template, i.e. the content is arranged into sections that appear in a logical sequence. The role of each section is indicated by labels on the right-hand side, but these are not part of the explications proper.

\subsection{Preview}

To present seven complex explications in the space available, it is necessary to confine the discussion and justification to key points. By way of overview, it will be helpful to make three general comments. First, even though in most cases I have been able to build on previous work, (re)formulating each one of these explications has been an arduous process. Most have presented numerous puzzles of expression connected with the challenge of capturing intricacies of meaning using a very small metalanguage.

A second issue (or pair of issues) concerns the optimal selection of semantic molecules and the structure of the semantic templates. I want to flag that I am proposing a new solution to a paradox concerning the role of 'animal [m]' as a semantic molecule of English. The paradox arises because from the intuitive point of view of an English speaker, dogs, horses, kangaroos, and so on, are clearly categorised as animals; and yet it is well-known that the meaning of this English word is rather language-specific. If 'animal [m]' is used as a taxonomic head, as it was in Goddard (2011), the implication is that the English-language conceptualisation of all the lower-level generic words is significantly different to that of closely related European languages. On the other hand, if 'living thing' or 'creature [m]' is used as the top-level taxonomic head and 'animal [m]' is omitted altogether, the explications seem to be missing an important element. Briefly, the solution proposed here is to include 'animals [m]', but not as a taxonomic head.

Third, there is the long-recognised issue of how much semantic detail deserves to be included in an explication (the "what's in, what's out?" question), and, relatedly, the question as to how much semantic variation there can be across English-speaking communities and between individuals. Wierzbicka (1985) distinguished between what she termed "concept maximum" and "concept minimum". The "concept maximum" designates what competent adult speakers know in virtue of knowing the language well, as evidenced by phraseology and collocation: a linguistically scaffolded, shared stereotype. It may include cultural knowledge and culturally-conditioned construals. The "concept minimum" can be thought of as the minimum collection of features that a person needs to know in order to recognise a given creature as an instance of, say, the category $d o g$, horse, or kangaroo. I accept the usefulness of this distinction, and in this study I am generally out to capture the concept maximum. Notwithstanding, however, it seems clear that for some words, speakers of some varieties of English have richer semantic entries than others because they have richer shared understandings of the concept in question. To open up this issue, section 5 considers two generic-level concepts which differ markedly in this respect: dogs and kangaroos. Section 6 is a concluding discussion. 


\section{A UNIQUE BEGINNER: 'CREATURE'}

It can be hypothesised that all or most languages share a rather simple "unique beginner" in the ethnozoological domain, explicated in [A] below. This explication is simpler than the version presented in Goddard (2011).

\section{[A] creatures}

something living

something like this can move

something like this can feel something

It must be admitted that the universality of this meaning has not yet been thoroughly tested and the picture is complicated, in some languages, by polysemy and other language-specific factors.

In Russian, the closest equivalent is (zhivye) sushchestva '(living) creatures'2, in Polish stworzenia. In German Tier(e) is probably the preferred equivalent. Though normally translated as 'animal(s)', it is much broader in its range of application and can be used freely about birds, insects, snails, and so on. For French, the best candidate is probably bête, for similar reasons. Both German Tier(e) and French bête(s) are likely to be polysemous, as suggested by the fact that bête, for example, normally suggests a large creature ${ }^{3}$.

As an example of a different kind of polysemy, in the Australian Aboriginal language Warlpiri the equivalent meaning appears to be expressible by the polysemous word kuyu, which also can have the narrower meaning 'edible creature, game', as well as 'meat'. Kuyu in both these narrower senses can apply equally well to all edible creatures, including birds, lizards and snakes. Both meanings are very frequent and salient but a broader meaning is also attested, for example, in the title of the Warlpiri booklet Kuyu Ngarninja-wangu ("Kuyu we do not eat") by Robertson George Jampijinpa (1980). Whether this broader meaning is precisely identical to 'creature' requires further research, but it seems clear that they are substantially equivalent.

\section{LIFE-FORM WORDS}

It is arguable that all or most languages have taxonomic heads comparable in meaning to 'birds' and 'fish'. To say this is not to claim that such words are absolute universals (cf. Goddard 2018: 57-59), because it is well established in the linguistic and anthropological literature that such words can differ in their range of application, especially in relation to large flightless birds and bats.

2 Sushchestva can also be understood as 'beings', consistent with its morphological makeup, though clearly it would not make sense to speak of a fish or snail as a 'being'. Together with the fact that sushchestva can be used about people, e.g. pisateli - eto verkhovnye sushchestva 'writers they are supreme beings', and about 'extraterrestrial beings' vnezemnye sushchestva, this indicates that sushchestva is polysemous between 'creatures' and 'beings'. The adjective zhivye 'living' serves to "select" the 'creature' meaning.

${ }^{3}$ All three languages also have other, more abstract-sounding and/or technical words, e.g. Russian sozdanie, tvorenie, tvar', French animal, créatures, German Lebewesen, but these are not preferred candidates in view of the existence of "plainer" and more stylistically versatile alternatives. 


\subsection{Birds}

Explication [B] follows the previously-proposed semantic template (see section labels at right-hand side), with the addition of a new second section (b) called Main Features.

A few selective comments follow. The wording of section (a) ('creatures [m] of one kind, there are many kinds of such creatures [m]') corresponds to Berlin's observation that life-form words are characterised by "polytypicity". (The expression 'such creatures' is a portmanteau for 'creatures like these'.) Explications for the molecules 'wings [m]', 'feathers [m]' and 'eggs [m]', used in section (b), are given in Appendix B. Needless to say, to avoid circularity, they are phrased without reference to birds. The third line of section (b) is phrased to allow for the existence of flightless birds, while acknowledging that birds are commonly thought of as being able to fly. Sections (c) and (d) capture, respectively, diversity in the range of places where birds live and where they are commonly found, and in their sizes. Provision for a range of habitats and sizes is typical for major life-form concepts.

In section (e), Body, the various parts of the bird's body design are described as being like human body-parts, such as 'head' and 'legs'. This detail of wording is necessary because the explications for 'head' and 'legs', and so on, are based explicitly on people's bodies (Wierzbicka 2007). Section (f), Behaviour, provides for the existence of flightless birds, as well as saying something about what birds eat. Section $(\mathrm{g})$, Sounds, is an important part of the bird concept, since many birds make distinctive speciesspecific sounds which are often pleasant to the ear. In connection with this last point, we can note the English use of the verb sing about birds, and expressions such as bird song and song birds; on the other hand, some birds, such as crows and parrots, are not said to 'sing', but to chirp, screech, caw, etc.

\section{[B] birds}

a. creatures $[\mathrm{m}]$ of one kind there are many kinds of such creatures [m]

WITH SUB-CATEGORIES

b. creatures [m] of all these kinds have wings [m], there are many many feathers [m] on [m] the wings [m]

MAIN FEATURES when they are very small, their bodies are inside eggs [m] when people think about them, they often think like this: "they can fly [m]"

c. many kinds of such creatures [m] live in places above the ground [m], often they are flying [m], sometimes they are in trees [m] some kinds live in places where there is much water [m], sometimes they are flying [m], sometimes they are on the water [m] some kinds, not many, live in places on the ground [m]

d. many kinds of these creatures [m] are small, some kinds are very small some kinds are big, some (not many) are very big

e. the bodies of these creatures [m] are not like the bodies of creatures [m] of other kinds
WHERE THEY LIVE

BODY 
their bodies are like this:

- one part of their bodies is like people's heads [m] two parts are like people's eyes [m], one of them is on one side head of the head [m], the other one is on the other side of the head [m]

— they don't have a part like people's nose [m], they don't have a part like people's mouth [m] in the place where these parts of people's face [m] are, these creatures [m] have another part, it is not like any part of people's body it has two parts, they are hard [m], one of them is above the other one

- two other parts of their bodies are like people's legs [m]

- one part of their bodies is not like any part of people's bodies this part is at the back [m] of the body

- these creatures [m] can have bodies of two kinds, like people can have bodies of two kinds there can be eggs [m] inside the bodies of creatures [m] of one of these two kinds

f. many kinds of these creatures [m] can fly [m], BEHAVIOUR some (not many) can't fly [m] these creatures $[\mathrm{m}]$ eat $[\mathrm{m}]$ very small things some of these very small things are living creatures [m], some are not living creatures [m]

g. many kinds of these creatures [m] SOUNDS often do something like people do with their mouths [m] when they want to say something people can hear something because of this sometimes when people hear it, they can know what kind of creature [m] it is, sometimes they can think: "this is like singing [m]"

Nothing has been included in explication [B] about nests, but probably this should be added.

\subsection{Fish}

The explication in [C] follows the same template as used for birds, except that two sections, Behaviour and Sounds, are omitted, and there is a final section 'Relation to People', which indicates the existence of fishing as a human activity.

Here are a few selective comments. In the final line of section (b), the word 'swim' has been avoided, since it is well known that in many languages one does not speak about fish "swimming". In section (c), it is assumed that 'sea [m]' is a widespread "approximate" semantic molecule. In the Body section, nothing is said about there being two kinds of bodies, i.e. male and female. In fact, fish bodies do come in two types but the differences are difficult to discern, and, in my view, do not form part of the general concept of fish.

\section{[C] fish}

a. creatures $[\mathrm{m}]$ of one kind there are many kinds of such creatures [m]

b. creatures [m] of all these kinds live in places WITH SUB-CATEGORIES where there is much water [m] they live in (inside) this water [m] 
they can move in this water [m] as they want

if they are not in water [m] for some time, they can't live

c. many kinds of these creatures [m] live in the sea [m] WHERE THEY LIVE many kinds live in other places where there is much water $[\mathrm{m}]$

d. some kinds of these creatures [m] are small, some kinds are very small some kinds are big, some (not many) are very big

e. the bodies of these creatures [m] are not like the bodies

BODY of creatures $[\mathrm{m}]$ of other kinds

their bodies are like this:

- they are long [m]

- they don't have parts like people's arms [m], they don't have parts like people's legs [m]

- they have some flat [m] parts on two sides of their bodies these parts can move when this creature [m] wants when this happens, the body can move in the water [m] as this creature [m] wants

- one part of their bodies is like people's heads [m] two parts of this part are like people's eyes [m], one part of this part is like people's mouth [m]

- they don't have a part of the head [m] like people's nose [m]

- one part of their bodies is not like any part of people's bodies, this part is at the back [m] of the body, this part can move

- there are many very small flat [m] thin [m] things on all sides of their bodies

f. people can eat [m] parts of the bodies of these creatures [m] because of this, some people do many things in many places where there is much water [m]

because they want some of these creatures $[\mathrm{m}]$ not to be in water [m] anymore

An issue which is open for discussion is whether there should be an additional 'How People Think About Them' section, as proposed in Wierzbicka (1985). Such a section seems well motivated for many generic-level words, but it is not clear whether the same applies for life-form words. In the case of fish, one candidate for such a section would be a component along the following lines: 'when something bad happens to their bodies, they don't feel something bad like people feel something when something bad happens to people's bodies'. This would capture an apparently widespread folk belief that fish do not feel pain.

\subsection{Minor life-form words}

Not all life-form concepts are as complex as 'fish' and 'birds', or as prolific as taxonomic heads; and not all have equal claim to the status of approximate or nearuniversals. On the contrary, it appears that languages may possess various minor, less well differentiated, life-forms (cf. Atran 2000). Consider the English word snakes. There are some primary lexemes for individual kinds of snake, e.g. python, viper, cobra, and (in Australia) death adder and taipan, but people are well aware that there are many other kinds which go unnamed. A tentative explication is given in [D].

\section{[D] snakes}

creatures [m]

there are many kinds of such creatures [m] 


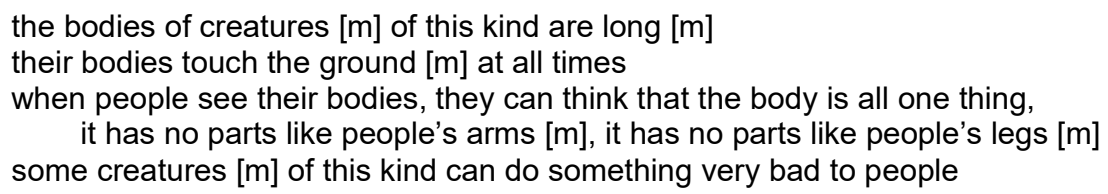

Spider deserves to be recognized as another minor life-form word of English, given the existence of primary lexemes like tarantula, daddy long-legs, and, in Australia, red back, funnel-web, and huntsman.

Languages vary in the number and semantic composition of these minor categories, and in whether or not they function as taxonomic heads. For example, Polish grzyby, the near-equivalent of 'mushroom', functions as a taxonomic head in words for various kinds of mushrooms, such as kurki, maślaki, koźlaki, prawdziwki, borowiki, rydze, pieczarki, and muchomory (Wierzbicka 2009).

\section{ANIMALS}

Explication [E] below is based on that presented in Wierzbicka (2013). The main difference that the molecule 'creatures [m]' is used in place of the expression 'living things'. There are a number of notable points. First and foremost, the initial component presents animals as a multi-category concept, i.e. not 'creatures [m] of one kind', but rather 'creatures $[\mathrm{m}]$ of many kinds'. This is the hallmark of a collective (as opposed to a taxonomic) hyponym (Goddard 2017).

Second, in section (b), there is an immediate physical comparison with people: 'their bodies are like people's bodies, not like the bodies of creatures [m] of many other kinds'. As we will see, throughout the explication there is a series of alignments and contrasts with the concept of people. This may seem unexceptional but not all languages do this - not even all European languages. As mentioned, if we compare English animals with its nearest counterpart in German, we see that German Tiere (singular: Tier) embraces a much broader range of creatures. Fish, birds, snakes, and even spiders and insects, can be regarded as Tiere (and likewise, in Danish, as $d y r$ ).

In section (c), 'Where They Live', we can see other components that help delimit the concept of animals. They are said to live in 'places where parts of their bodies can often touch the ground [m]'. This serves to exclude fish and other aquatic creatures, but it does not exclude tree-dwelling creatures such as squirrels and monkeys. Living on land, squirrels and monkeys can still often be in contact with the ground, even though they spend much of their time in the trees. Skipping down to section (g), the last two components provide for the existence of numerous wild animals, and also for a number of animal kinds that live in association with people.

A couple of further points follow. In section (d), the Body section, it is stated that many animals have two legs at the front and two at the back (this wording allows for exceptions such as kangaroos and chimpanzees). Section (e), 'Male and Female', says that their bodies come in two kinds, one with some parts 'like parts of women's [m] bodies' and the other with some parts 'like parts of men's [m] bodies'. The comparison with people continues in section (f), in relation to how animals are 'born [m]' and cared for after birth. 
Finally, there is a section 'How People Think About Them', which sums up people's ambivalent attitudes towards animals: recognising that they can do many things and feel many things, but equally that they lack human capacity for knowledge, speech and thought, and in particular that they lack any "sense of right and wrong" ('they can't think like this about something: 'it will be good if I do this, it will be bad if I do this'); cf. words and expressions such as animalistic, like an animal, they behaved like animals, and the like.

\section{[E] animals}

a. creatures [m] of many kinds

MACRO-CATEGORY

b. people can think about them like this:

MAIN FEATURES

"their bodies are like people's bodies, not like the bodies

of creatures [m] of many other kinds"

WHERE THEY LIVE

c. such creatures [m] live in places of many kinds people can think about it like this:

"they live in places where parts of their bodies can often touch the ground [m]"

d. many parts of their bodies are like parts of people's bodies

BODY

— one part is like people's head [m]

— one part is like people's mouth [m]

- head

— some parts of their bodies are like people's legs [m]

- mouth

when people think about these parts of the bodies of such creatures [m],

- legs

they can think like this:

"two of these parts are at the front [m] of the body, two others are

at the back [m] of the body"

at the same time people can know that the bodies of some kinds

of such creatures $[\mathrm{m}]$ are not like this

- one part of the bodies of such creatures $[\mathrm{m}]$ is not like

- tail any part of people's bodies

this part is at the back [m] of their bodies, it is long [m]

this part can move when this creature [m] wants it

e. creatures [m] of all these kinds can have bodies of two kinds

like people can have bodies of two kinds

some parts of the bodies of one of these two kinds are like some parts

of men's [m] bodies,

some parts of the bodies of the other kind are like some parts

of women's [m] bodies

f. people can think about it like this:

YOUNG

because creatures $[\mathrm{m}]$ of all these kinds have bodies of these two kinds,

small creatures [m] of these kinds can be born [m] like people are born [m]

before they are born [m], their bodies are for some time inside the body of a big creature $[\mathrm{m}]$ of the same kind,

like a child's [m] body is inside the body of this child's [m] mother [m] before this child $[\mathrm{m}]$ is born

for some time after these small creatures [m] are born [m], they are often with this big creature [m],

like a child [m] is often with its mother [m] for some time after it is born [m]

this big creature $[\mathrm{m}]$ can do some good things for these small creatures $[\mathrm{m}]$ during this time, like a child's [m] mother [m] can do some good things for this child [m] for some time after this child [m] is born [m] 
g. people can think about these creatures [m] like this:

RELATION TO PEOPLE "there are many kinds of these creatures [m] creatures [m] of some of these kinds live in places where people live sometimes people want this because it can be good for people, sometimes people don't want this creatures [m] of some other kinds live far from places where people live they don't want to live near places where people live at the same time, people don't want them to live near places where people live

because creatures $[\mathrm{m}]$ of some of these other kinds can do very bad things to people"

h. people can think about creatures [m] of all these kinds like this:

"they can do many things, they can feel many things"

at the same time, people can think about them like this:

HOW PEOPLE THINK ABOUT THEM

"they can't know many things like people know many things

they can't say something with words like people can say something with words they can't think like people can think, they can't think like this about something:

'it will be good if I do this, it will be bad if I do this"”

\section{GENERIC-LEVEL WORDS}

As mentioned, Goddard (2011) had proposed that in English the word 'animal' functions as a taxonomic head in the explications for individual species words such as $d o g$, cat, mouse, and so on. This proposal brought with it certain difficulties, however, because it seems counter-intuitive to say that the semantics of English dog and German Hund, for example, are different at the very highest level of categorisation. The present paper proposes an alternative strategy, according to which 'animal [m]' does appear in the explication of $d o g$ and kangaroo - though not as a taxonomic head.

Wierzbicka (1985) explicated many generic-level terms, including dogs, cats, horses, cows, tigers, squirrels, foxes, wolves, lions, and elephants, among others. See Goddard (2011) for more recent explications of cats, mice, and rats. As noted by Wierzbicka (1985), people's general knowledge about an animal species greatly depends on its role in human life: expressions such as domestic animals, farm animals, zoo animals and wild animals reflecting different domains and degrees of contact.

The template used below follows Wierzbicka $(1985,2013)$ with the following sections (except that with $\operatorname{dog} s$, there is a special 'Exceptional Relation With People' section inserted in second position): Category, Where They Live, Size, Body, Sounds, Behavior, Relation to People, How People Think About Them. One open question is whether the final section deserves to be included or whether it should be dealt with as a cultural script; see end of section 5.1.

\subsection{Dogs}

Explication [F] is one of the longest and most complex of all generic-level explications, which is only to be expected, given that dogs are the most familiar of all domestic animals. Indeed, it is believed that they co-evolved with humans from wolf-like ancestors, this accounting for their highly developed social cognition (Hare, et al. 2002). Dogs also come close to being a "universal animal", in the sense of being known by the vast majority of the world's cultures, albeit with differing roles and cultural attitudes. Here we focus on $\operatorname{dog} s$ as they are seen in the Anglo English linguaculture. 
The phraseology associated with $\operatorname{dog} s$ is extensive, including body-parts and endonyms, vocalisations, stage of life, words related to keeping and looking after dogs, compounds related to "working dogs", commands, breeds (specifics), cousin species, and numerous sayings and proverbs. Space prohibits reviewing these in any detail here.

- paws, snout, wag tail $\bullet$ bark, growl, whimper, whine, howl, snarl, pant, yelp

- woof-woof, bow-wow - puppy, pup, bitch - leash, collar, muzzle, kennel, dog food walk the dog, train a dog, wash the dog, dog-trainer $\bullet$ farm dog, sheep dog, cattle dog, working dog, hunting dogs, police dogs, security dogs, guard dogs, sniffer dogs, guide dogs, seeing-eye dogs, show dogs $\bullet$ commands (fetch!, sit!, lie down!, come!, heel!) • mongrel, mutt, dog breeds (Labrador, poodle, terrier, beagle, greyhound, Corgi, etc.) $\downarrow$ wolf, dingo, hyena

- sick as a dog, treated like a dog, a dog's life, in the dog house, die like a dog - man's best friend, you can't teach an old dog new tricks, let sleeping dogs lie.

There are many aspects of explication [F] that warrant discussion. Space permits only five observations at this point. First, the explication asserts "canine exceptionalism" from the onset, in sections (a) and (b), and this is elaborated in great detail in the lengthy section (g) 'Relation to People'. Second, the Size and Body sections, (c) and (d) respectively, provide for a great deal of diversity. Third, section (e) attempts to capture some of the complexities of dog sounds, in particular, the "messages' expressed (or thought to be expressed) by barking and by growling. The existence of howling (whimpering, etc.) is also briefly alluded to. Fourth, the Behaviour section (f) includes not only some typical behaviours and abilities of dogs, but also their tail wagging and their sense of smell. Fifth, the 'Relation to People' section (g) is extensive, including their role as pets and companions, the special relationship that dogs can have with their owner or master, their territoriality (though possibly this should be positioned under Behaviour), and how they can help people in many tasks. The possibility of people mistreating dogs is also mentioned. I reserve discussion of the final section (h) until after the explication.

Along with the astonishing degree of semantic detail, a striking feature of the explication is how frequently it attributes human-like capacities of thinking (and even, saying) to dogs, albeit the model thoughts are short and context-bound.

\section{$[\mathrm{F}] \operatorname{dogs}$}

a. creatures [m] of one kind

CATEGORY they are animals $[\mathrm{m}]$, at the same time they are not like animals $[\mathrm{m}]$ of other kinds

b. they want to do many things with people, they can do many things EXCEPTIONAL RELATION as people want

many of them live with people because people want this many of them are like this: when people say some words to them because these people want them to do something, they can know what these people want to say

c. some of them are big, someone can't pick up [m] one like this some of them are small, someone can pick up [m] one like this with two hands [m] some are very small, some are very big 
d. their bodies are like this:

- one part of the head [m] sticks out [m], this part is below the eyes [m]

BODY the nose $[\mathrm{m}]$ is part of this part of the head [m], the mouth [m] is part of this part of the head [m]

- their ears [m] are on two sides of the top [m] of the head [m]

- they have sharp [m] teeth [m] they have long [m] tongues [m], often people can see parts of their tongues [m]

- they have two legs [m] at the front [m] of the body they have two legs $[\mathrm{m}]$ at the back [m] of the body

- some of them have long [m] legs [m], some don't have long [m] legs [m]

- many of them have a long [m] tail [m], some don't have a long [m] tail [m]

e. they can do some things with the mouth [m], when they do this, people can hear something of one kind because of it, someone far away can hear it when people hear something of this kind, they can think about it like this:

"it wants to say something like this: 'something is happening here now,

I feel something now because of it, I want to do something now because of it' "

they can do some other things with the mouth [m], when they do this, people can hear something of another kind because of it

when people hear something of this other kind, they can think about it like this:

"it wants to say something like this to someone: "I feel something bad towards you,

I want to do something bad to you with my teeth [m]"

they can do some other things with the mouth [m] — other sounds

when people hear something because of this, they can think about it like this:

"it is feeling something very bad now"

f. they can do things like this:

BEHAVIOUR

- when they want to be somewhere else after a short time, they can move quickly [m]

- they can do many things with their mouths [m] they can bite $[\mathrm{m}]$ other creatures [m], they can bite [m] people they can pick up [m] something with their mouth [m], they can hold [m] something with their mouth [m]

- often when they want to eat [m] something, they want to eat [m] meat [m]

- sometimes they kill [m] creatures [m] of other kinds

- when they feel something good towards someone, they often do something with their tails [m]

when they do this, the tail [m] moves many times in a short time

- when one of them is in a place, it can know many things about this place because it can do something with the nose [m]

if someone was in this place not long before, it can know it

g. many people feel good things towards them

- many of them live in people's houses [m] because these people want this,

many of them live near people's houses [m] because these people want this

- often these people think about such animals [m] like this: "this is someone"

they do some good things for this animal [m]

they often want it to know that they feel something good towards it

at the same time they want to know that it feels something good towards them

- sometimes it is not like this, sometimes some people do very bad things to animals [m] of this kind

- many animals [m] of this kind think about someone like this: "this someone is not like any other someone"

- tail wagging

- growling

Be

hen one of them thinks like this about someone, it wants to often

be with this someone, it wants to often do things with this someone

- sometimes animals $[\mathrm{m}]$ of this kind think about a place like this:

"this place is not like any other place"

— sense of smell

RELATION TO PEOPLE - domestic

when one of them thinks like this about a place, it wants

other animals $[\mathrm{m}]$ not to be in this place 
- some animals [m] of this kind can do things of some kinds as people want it can be good for people if these animals [m] do these things

h. when people think about animals [m] of this kind, they often think about them like this:

HOW PEOPLE THINK

"animals [m] of this kind are like no other animal [m] ABOUT THEM when someone is with one of them, this someone can feel something good like someone can feel when this someone is with other people" at other times they think about them like this:

"they are not like people sometimes they do things with their parts of their bodies not like people do if people did such things, it would be very bad"

There are several notable aspects surrounding the 'How People Think About Them' section. First, the wording of the introductory component ('when people think about animals [m] of this kind, they often think about them like this: ...') is slightly different to that of the comparable section in explication [E] ('people can think about creatures [m] of all these kinds like this: ...'). This is a minor, and presumably innocuous, difference due to the different structure of generic-level, as opposed to life-form, concepts. Second, there is the more problematical issue of how to capture the idea that $\operatorname{dog} s$ can be thought of as sexually loose, i.e. indiscriminate in their mating, as well as sometimes engaging in other potentially disgusting bodily behaviours, e.g. licking or sniffing each other's genitals. The idea behind the component is to indicate the general nature of such behaviours without going into too much detail.

A final and more general question is whether a 'How People Think About Them' section deserves to be included in the semantic explication at all. An alternative approach would be to represent the same content using a kind of cultural script (Goddard 2009, Wierzbicka 2015). Cultural scripts, briefly, are the NSM mechanism for representing social attitudes and norms, especially concerning ways of speaking, thinking and acting. They typically begin with a component like: 'many people think like this: ....' or 'people often think about it like this: ....'. To depict commonly-held attitudes about dogs and other species, the following framing components might work:

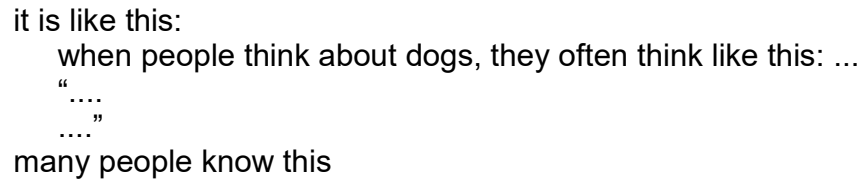

This issue is not a simple one and it is not possible to explore all the ramifications and possibilities here. Whatever the appropriate mechanism for capturing cultural attitudes towards $\operatorname{dogs}$ (or any other species), it is clear that they can differ widely across cultures and thus must be captured as part of any comprehensive ethnolinguistic description.

\subsection{Kangaroos}

From an ethnosemantic point of view, kangaroos contrast with dogs in many ways. They are little known by personal contact to English speakers outside Australia, but are widely known by reputation, as it were. Kangaroo was one of the earliest loan words into English from an Australian Aboriginal language, the Guugu Yimidhirr language of north Queensland (Haviland 1977). It was first recorded by the botanist Joseph Banks during 
Captain Cook's 1770 voyage to Australia, and on account of the strangeness of the animal (to Europeans), the word kangaroo quickly became internationally well-known.

Kangaroos are well represented in films, television, books, toys and souvenirs around the world. They are strongly associated with Australia, and indeed, the kangaroo is a symbol of Australia. There is a kangaroo on the Australian coat of arms (along with an emu), a kangaroo in motion is the logo of the national airline Qantas, and numerous Australian sporting mascots and other logos feature kangaroos. Visitors to Australia will find a kangaroo (a small group of them) on the $\$ 1$ coin. Figure 1 shows some visual images that are familiar to most Australians.

The phraseology associated with kangaroos is not as varied as that for dogs, which of course makes sense given that kangaroos are wild animals. With the exception of pouch, and possibly joey (young kangaroo), much of it is not widely known outside Australia. In Australia, kangaroos are often called roos. They are very common, so much so that on many country roads people worry about hitting a roo (hence the value of having a roo bar fitted to your car). "Kangaroo crossing" road signs are common. The form -roos is used in the names or nicknames of national sports teams, such as the socceroos and hockeyroos (men's soccer and women's field hockey teams, respectively) and jillaroos, the national women's rugby team. In Australia, most people would be familiar with the collective noun $m o b$, referring to a group of kangaroos (often 6-10, or more, in number).

Kangaroo meat (roo meat) is available in many supermarkets. People know that kangaroos are not farmed and that kangaroo meat is obtained from commercial shooting of wild kangaroos. The collocations roo shooter and roo shooting are well attested (also kangaroo hunting, kangaroo hunter, and less so the term kangaroo harvest). Kangaroos are also shot as a population control measure on farms and in national parks, a controversial practice known as kangaroo culling (also, the kangaroo cull).
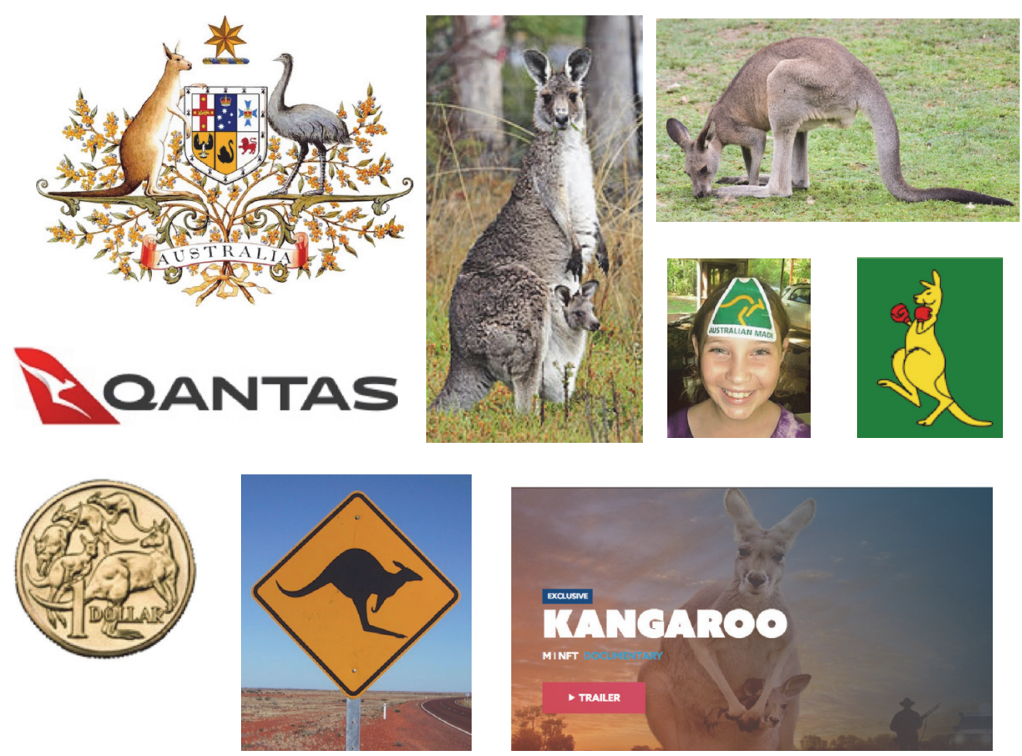

Figure 1: Some familiar images and iconographic uses of kangaroo in Australia. At the bottom right is an advertising still for a 2018 movie "Kangaroo". Note the small figure of the roo shooter in the background 
Explication [G] is intended to capture the "concept maximum" of kangaroo in Australian English, supported by the linguistic and other evidence summarized above. How much of this semantic content is shared across English speakers will be discussed in section 6 .

A few observations follow. In relation to section (a), it is interesting to note that in reality "the kangaroo" is not a single species at all. There are several distinct species of kangaroo, and as well there are wallabies, which are smaller but have a similar body shape (they are all technically macropods). Nonetheless, from the semantic-conceptual point of view of Anglo Australians, kangaroos are 'creatures [m] of one kind'.

Section (b) is notable for including the country word 'Australia [m]' as a semantic molecule in the 'Where They Live' section. It is more usual to find words for "habitat zones", such as 'jungle' or 'desert', in this section (or expressions like 'places where there is a lot of snow'), though presumably 'Africa [m]' appears as a molecule in English words like lion and giraffe. As it happens, there are a large number of species endemic to Australia, and some of them, such as koala, dingo, and platypus, are part of the everyday, non-specialist lexicon. As with kangaroos, there would be a case for including 'Australia [m]' in explications for these words; cf. also Bromhead (2011) on the Australian English sense of 'the bush'.

The idea behind section (c) is that the Size component depends on comparison with the human body, but the exact wording is open to question. It would be possible to use the expression 'someone's body', but intuitively this sounds vague, even odd, and allows the unwanted possibility that the 'someone' could be a child. The solution adopted here is to make the comparison with a 'man's [m] body'. Needless to say, it gives one pause to think that the implicitly anthropocentric standard of comparison may be "crypto-gendered".

The Body section (d) is detailed, with attention paid to the unusual non-quadrapedal body, the long feet, long tail, typically upright stance, and so on. The description of the legs as 'strong [m]' echoes the common expression "powerful hind legs" and in relation to the feet it is interesting to note the Latin name for the genus, i.e. macropod, literally, 'large foot'. The internal ordering in this section, i.e. with legs coming first, is motivated by its conceptual prominence against the prototypical four-legged "model animal". It should also be noted that the Marsupial aspects of the kangaroo's body (pouch, etc.) are not included here but are given in a separate section: section (g). This is because these components seem to require coordinated use of "body" and "behavior" components, on account of the relationship between 'pouch' and 'joey'.

The Sounds (e) section of the template is empty.

In section (f), the words 'jump' and 'hop' have not been used, even though they are commonly used to describe the kangaroo's mode of locomotion. There are three reasons: first, the basic sense of 'jump' is a single action in one place, which creates problems with using it as a molecule to describe repeated actions; second, it would be hard to choose between 'jump' and 'hop'; third, to describe the "bounding" forward motion requires such an amount of additional detail that there is little to be gained by employing 'jump' or 'hop' as molecules. 
As mentioned the "marsupial" aspects of the explication, essentially, the distinctive 'pouch' of the female kangaroo, and its role in sheltering and nurturing the young 'joey', are dealt with in section (g). Some aspects of this section are no doubt unknown to many English speakers outside Australia, and probably to some Australians as well. Note that the word 'pouch' is included, not as a molecule but as a name: 'it is called [m] a pouch'.

The Relation to People section (h) deals with kangaroos as a source of meat, and with the fact that they are hunted and 'culled'. The final 'How People Think About Them' section attempts to capture the role of kangaroos as an international symbol of Australia: 'when people in many countries [m] think about these animals [m], they often think about Australia [m] at the same time'. The form of this component is perhaps not optimal.

\section{[G] kangaroos}

a. creatures $[\mathrm{m}]$ of one kind they are animals [m], at the same time their bodies are not like the bodies of many other animals [m]

b. they live in many places in Australia [m] WHERE THEY LIVE

c. they are big SIZE their bodies can be big like a man's [m] body

CATEGORY

d. their bodies are like this: the two legs [m] at the front [m] of the body are not like other animals' [m] legs [m] they are like small arms [m] the two legs [m] at the back [m] of the body are big, they are very strong [m] at the bottom [m] of the legs [m] at the back [m], there are two long [m] feet [m]

- they have a very long [m] tail [m] - tail the part of the tail [m] close to the back [m] of the body is very thick [m] when they are not moving, the tail [m] touches the ground [m]

- the bottom [m] part of their body is very wide [m]

- the head [m] is small one part of the head [m] sticks out [m], this part is below the eyes [m] the nose [m] is part of this part of the head [m] the mouth [m] is part of this part of the head [m]

— their two ears [m] stick up [m] on two sides of the top [m] of the head [m]

- when they are not moving, their head [m] is often above all the other — upright posture parts of their body, like a person's head [m] is above all the other parts of a person's body when the person is standing [m]

e. -

SOUNDS

f. animals [m] of this kind can do things like this:

- when they want to be somewhere else after a short time, they move not like many other animals [m]

when they do it, the same thing happens many times

it happens like this:

- for a very short time the front [m] parts of the feet [m] touch the ground [m], at this time the tail is high (= far) above the ground [m]

- after that the whole body is above the ground [m] for some time

- during this time it moves forwards [m] quickly [m]

- after that it touches the ground [m] like before

when they do this, they can move quickly [m]

— often when they want to eat [m] something, they want to eat [m] grass [m] _ food

— often people can see many animals [m] of this kind in one place

$-\mathrm{mob}$ 
g. animals $[\mathrm{m}]$ of this kind have bodies of two kinds,

like other animals $[\mathrm{m}]$ have bodies of two kinds

before one of them is born [m], its small body is inside the body of a big animal [m]

of one these two kinds, like a child [m] is inside its mother's body [m] before it is born [m]

after it is born [m], the body of the small one is very very small,

not like many other animals $[\mathrm{m}]$

before it can be big, it has to (= can't not) be for some time inside

a part of its mother's $[\mathrm{m}]$ body

this part is not like any other part of this animal's [m] body, it is called [m] 'a pouch'

it is at the front [m] of the big animal's [m] body, in the middle [m]

it is open $[\mathrm{m}]$ at the top $[\mathrm{m}]$

after it is born [m], a small animal [m] of this kind lives inside this part

for some time, when its body is very very small, it is always inside this part

after its body is not very very small anymore, its small head [m] can be not

inside this part at some times (people can see the head [m] sticking out [m])

after some time more, when its body is big, the small animal [m]

can be not inside this part for a short tine

it can be eating $[\mathrm{m}]$ grass $[\mathrm{m}]$ near its mother $[\mathrm{m}]$ for a short time

if it feels something bad during this time, it can jump [m] inside this part like before

h. - people can eat meat $[\mathrm{m}]$ of animals $[\mathrm{m}]$ of this kinds

RELATION

- sometimes some men kill $[\mathrm{m}]$ them with guns $[\mathrm{m}]$ because they know that many people think like this: "it is good if people can eat

TO PEOPLE this meat [m] when they want"

- sometimes some men [m] kill [m] them with guns [m]

because some people think like this about a place:

"there are very many animals $[\mathrm{m}]$ of this kind in this place, this is bad for this place"

i. - when people in many countries [m] think about these animals [m], they often think about Australia $[\mathrm{m}]$ at the same time

HOW PEOPLE THINK ABOUT THEM

Needless to say, there are many facts about kangaroos which are not mentioned in this explication; for example, the use of the tail in pushing forward while grazing and hopping, the fact that kangaroos have claws, that there is a notable size differences between male and female, that Aboriginal people hunt kangaroos for meat and many other purposes. I have tried to stick to aspects which are well supported by linguistic evidence.

\section{DISCUSSION AND CONCLUSION}

The present study has sought to revisit Wierzbicka's (1985) ground-breaking explorations into the semantics of words for natural kinds, and to update and augment her many insights from the perspective of the NSM approach in its current stage of development, more than three decades later.

The most striking claim remains that it is indeed possible to explicate the conceptual content of natural kind terms, given detailed attention to linguistic evidence, but that such explications are astonishingly complex — both in their sheer length (typically 3040 lines of semantic text) and in the number of semantic molecules involved (more than 50 unique molecules in this study alone). Many of the semantic molecules required for ethnozoological concepts are not specific to this domain, e.g. words for body-parts, physical qualities, environmental words, some action and activity verbs, but others are: specifically, the higher-level categories such as 'creatures', 'animals', 'birds', and 'fish'. 
The present study has focused on the English language, while acknowledging that the near-equivalents of most of the words explicated, including those designating higherlevel categories, vary across languages.

Clearly, semantic templates play an indispensable role in disciplining the vast semantic complexity of ethnozoological concepts. The templates, shared by numerous words from the same domain, provide a stable frame (like a questionnaire or checklist, Wierzbicka 1985: 192) which can be filled out and elaborated over childhood as one acquires more and more knowledge and integrates it into the updated cognitive model. The template concept helps us understand how one's model of an unfamiliar species may have "placeholder" sections which are very sketchy or even blank, and - evidently there can be variation between speech communities, and, presumably, even between individual speakers of a single language. The idea of "concept maximum" and "concept minimum" are useful constructs to help support discussion of such variation.

It must be remembered that the extent to which a speech community or individual approaches the concept maximum for a given species does not depend only, or even mainly, on their personal contact with the species in question. In many cases, the great majority of one's semantic knowledge is linguistically mediated, i.e. acquired from discourse. Yet the volume, detail and character of discourse about animals differs according to physical, environmental and cultural setting. In Australia, for example, kangaroos feature in discourse to a much greater extent than say, badgers or beavers, though the opposite would be the case in England or Canada, respectively. As Wierzbicka (1985: 223) put it: "having said all this I feel it should be admitted that folk names of biological genera ... do seem to be more subject to interpersonal variation than nearly all other kinds of concepts encoded in natural language".

\section{Appendix A: Semantic primes}

Semantic primes (English exponents) grouped into related categories

\begin{tabular}{|l|l|}
\hline I, you, someone, something thing, people, body, kinds, parts & Substantives \\
\hline this, the same, other $\sim$ else & Determiners \\
\hline one, two, much many, little few, some, all & Quantifiers \\
\hline good, bad, big, small & Evaluators and Descriptors \\
\hline know, think, want, don't want, feel, see, hear & Mental Predicates \\
\hline say, words, true & Speech \\
\hline do, happen, move & Actions, Events, Movement \\
\hline be (somewhere), there is, be (someone/something) & Location, Existence, Specification \\
\hline (is) mine & Possession \\
\hline live, die & Life and Death \\
\hline $\begin{array}{l}\text { when time, now, before, after, a long time, a short time, for some } \\
\text { time, moment }\end{array}$ & Time \\
\hline where $\sim$ place, here, above, below, far, near, side, inside, touch & Locational \\
\hline not, maybe, can, because, if, very, more, like & “Logical” Concepts \\
\hline
\end{tabular}

Notes: - Exponents of primes can be polysemous, i.e. they can have other meanings in addition to the semantically primitive meaning - Exponents of primes may be words, bound morphemes, or phrasemes - They can be formally complex - They can have language-specific combinatorial variants or "allolexes" (indicated with $\sim$ ) - Each prime has well-specified syntactic (combinatorial) properties. 


\section{Appendix B: Explications for semantic molecules: 'eggs', 'wings', 'feathers'}

\section{eggs}

things of one kind

when people see one of these things, they can know that some time before

it was inside the body of a creature $[\mathrm{m}]$ of one kind

people can know that there can be a small creature [m] of the same kind inside it

at the same time they know that there can be something else inside it, they can know

that people can eat $[\mathrm{m}]$ this something else (this other stuff)

things of this kind are small, someone can hold [m] one of them in one hand [m]

they are smooth $[\mathrm{m}]$

people know that when someone's hands [m] touch one of these things on all sides, this someone can think: "this is like something round [m]"

people know that if something hard [m] touches one of these things quickly [m], something can happen to it in one moment because of this

they can know that if this happens, after this, this thing can be not one thing anymore

- Note: There is another egg meaning, basically, 'chicken egg'.

\section{wings}

two parts of the bodies of some creatures [m]

they are on two sides of the bodies of these creatures [m]

they can move as this creature [m] wants

because their bodies have these parts, these creatures $[\mathrm{m}]$ can move as they want in places above the ground [m]

\section{feathers}

things of one kind

they are parts of the wings [m] of some creatures [m]

when people see the wings [m] of these creatures [m], they can see many of these things there

if people see things of this kind somewhere else at some time, they can know that before

they were part of the body of one of these creatures [m]

people can think about things of this kind like this:

"many parts of these things are soft [m]

one part is not soft [m], this part is something long [m], it is in the middle [m] of this thing

one small part of this long thing is sharp [m]

when things of this kind are part of the body of a creature [m], this small part is

inside this creature/s [m] skin [m]

(C) Cliff Goddard, 2018

\section{REFERENCES}

Apresjan, Ju D. (1969). O yazyke dlya opisaniya znachenii slov. Izvestiya Akademii Nauk SSSR, Seriya Literatury i Yazyka, 28, 415-28.

Apresjan, Ju D. (1992[1974]). Lexical Semantics: User's Guide to Contemporary Russian Vocabulary. Ann Arbor: Karoma. [Orig. published in 1974 as Leksicheskaya semantika - sinonimicheskie sredstva yazyka (In Russ.), Moskva: Nauka].

Apresjan, Ju D. (2000). Systematic lexicography. (Windle, K. Trans.). Oxford: Oxford University Press.

Atran, S. (1990). Cognitive foundations of natural history. Cambridge: Cambridge University Press.

Berlin, B. (1992). Ethnobiological classification: Principles of categorization of plants and animals in traditional society. Princeton, N.J.: Princeton University Press. 
Bromhead, H. (2011). The bush in Australian English. Australian Journal of Linguistics, 31, 445 - 471.

Brown, C. (1979). Folk zoological life forms: Their universality and growth. American Anthropologist, $81,791-817$.

Goddard, C. (ed.). (2008). Cross-linguistic semantics. Amsterdam: John Benjamins.

Goddard, C. (2009). Cultural scripts. In Senft, G., Östman, J-O, \& Verschueren, J. (eds.), Culture and language use. Amsterdam: John Benjamins, 68-80.

Goddard, C. (2011). Semantic analysis. A practical introduction. Revised 2nd edition. Oxford: Oxford University Press.

Goddard, C. (2012). Semantic primes, semantic molecules, semantic templates: Key concepts in the NSM approach to lexical typology. Linguistics, 50(3), 711-743.

Goddard, C. (2016). Semantic molecules and their role in NSM lexical definitions. Cahiers de lexicologie 2016-2, № 109, 13-36.

Goddard, C. (2017). Furniture, vegetables, weapons: Functional collective superordinates in the English lexicon. In Ye, Z. (ed.) The semantics of nouns. Oxford: Oxford University Press, $246-281$.

Goddard, C. (2018). Minimal English: The science behind it. In Goddard, C. (ed.) Minimal English for a global world: Improved communication using fewer words. London: Palgrave Macmillan, 29-70.

Goddard, C. \& Wierzbicka, A. (eds.) (2002). Meaning and universal grammar: Theory and empirical findings, 2 vols. Amsterdam: John Benjamins.

Goddard, C. \& Wierzbicka, A. (2014). Words and meanings: Lexical semantics across domains, languages and cultures. Oxford: Oxford University Press.

Haviland, J. B. (1974). A last look at Cook's Guugu-Yimidhirr wordlist. Oceania, 44 (3), 216-232. [http://pages.ucsd.edu/ jhaviland/Publications/HavilandOceania.pdf]

Kripke, S. (1977). Naming and necessity. In Davidson, D. \& G. Harman (eds.), Semantics of natural language. Dordrecht: Reidel, 253-355.

Hare, B., Brown, M., Williamson, K. \& Tomasello, M. (2002). The domestication of social cognition in dogs. Science 298, 1634-1636.

Rosch, E. (1977). Human categorization. In Warren, N. (ed.), Advances in cross-cultural psychology. Vol. 1. London: Academic Press, 1-49.

Rosch, E. (1978). Principles of categorization. In Rosch, E. \& B. Lloyd (eds.), Cognition and categorization. Hillsdale, NJ: Lawrence Erlbaum, 27-48.

Wierzbicka, A. (1985). Lexicography and conceptual analysis. Ann Arbor: Karoma.

Wierzbicka, A. (1996). Semantics: Primes and universals. New York: Oxford University Press.

Wierzbicka, A. (2007). Bodies and their parts: An NSM approach to semantic typology. Language Sciences, 29(1), 14-65.

Wierzbicka, A. (2009). The theory of the mental lexicon. In Kempgen, S., P. Kosta, B. Tilman \& K. Gutschmidt (eds.), The Slavic languages: An international handbook of their structure, their history and their investigation. Berlin: Mouton de Gruyter, 848-863.

Wierzbicka, A. (2013). Polish zwierzęta 'animals' and jabtka 'apples': an ethnosemantic inquiry. In Głaz, A., Danaher, D.S. \& Łozowski, P. (eds.), The linguistic worldview: Ethnolinguistics, cognition, and culture. London: Versita, 137-159.

Wierzbicka, A. (2014). Imprisoned in English: The hazards of English as a default language. New York: Oxford University Press.

Wierzbicka, A. (2015). Language and cultural scripts. In Sharifian, F. (ed.), The Routledge handbook of language and culture. Routledge, 339-56.

Ye, Z. (ed.). (2017). The semantics of nouns. Oxford: Oxford University Press. 


\section{Article history:}

Received: 10 April 2018

Revised: 25 May 2018

Accepted: 30 May 2018

\section{История статьи:}

Дата поступления в редакцию: 10 апреля 2018

Дата принятия к печати: 30 мая 2018

\section{For citation:}

Goddard, Cliff (2018). A Semantic Menagerie: The Conceptual Semantics of Ethnozoological Categories. Russian Journal of Linguistics, 22 (3), 539-559. doi: 10.22363/2312-9182-2018-223-539-559.

\section{Для цитирования:}

Goddard, Cliff. A Semantic Menagerie: The Conceptual Semantics of Ethnozoological Categories // Вестник Российского университета дружбы народов. Серия: Лингвистика = Russian Journal of Linguistics. 2018. T. 22. № 3. C. 539-559. doi: 10.22363/2312-9182-2018-22-3-539-559.

\section{Bionote:}

CLIFF GODDARD is Professor of Linguistics at Griffith University. He is a leading proponent of the Natural Semantic Metalanguage approach to semantics and its sister theory, the cultural scripts approach to pragmatics, also known as ethnopragmatics. His recent publications include the edited volume Minimal English for a Global World (2018 Palgrave), Words and Meanings: Lexical Semantics Across Domains, Languages and Cultures (co-authored with Anna Wierzbicka; 2014 OUP), the textbook Semantic Analysis (2nd ed., 2011 OUP) and Ten Lectures on Natural Semantic Metalanguage (2018 Brill).

Contact information: E-mail: c.goddard@griffith.edu.au

\section{Сведения об авторе}

КЛИФФ ГОДДАРД - профессор лингвистики в Университете Гриффит (г. Брисбен, Австралия). Он является ведущим разработчиком Естественного Семантического Метаязыка в семантике и теории культурных скриптов в прагматике, также известной как этнопрагматика. Среди его недавних публикаций: сборник статей под его редакцией Minimal English for a Global World (Минимальный английский для глобального мира) (2018, Palgrave), книга в соавторстве с Анной Вежбицкой Words and Meanings: Lexical Semantics Across Domains (Слова и значения: лексическая семантика в разных языках и культурах) (2014, Oxford University Press), второе издание учебника Semantic Analysis (Семантический анализ) (2011, Oxford University Press) и Ten Lectures on Natural Semantic Metalanguage (Десять лекиий по Естественному Семантическому Метаязыку) (2018, Brill).

Контактная информация: c.goddard@griffith.edu.au.

\section{ACKNOWLEDGEMENTS}

This study is a way-station an ongoing program of semantic inquiry into ethnobiology. Much of the work reported was co-developed with Anna Wierzbicka. Some of the material appeared in Goddard (2011), though all the explications have been revised. The material on kangaroos was presented at the 2018 Semantic Workshop at Australian National University.

\section{БЛАГОДАРНОСТИ}

Данная работа является частью проекта по семантическим исследованиям в сфере этнобиологии, в разработке которого активное участие принимала Анна Вежбицкая. Часть материала была ранее опубликована в (Goddard 2011), однако все толкования в данной статье обновлены. Материал по кенгуру был представлен на ежегодном Семинаре по семантике в 2018 в Австралийском национальном университете. 